\title{
Isolated growth hormone deficiency - a rare, but treatable cause of low stature
}

\author{
Raluca Maria Vlad ${ }^{1,3}$, Delia Irina Nicolaescu², Alice loana Albu ${ }^{2,3}$ \\ $13^{\text {rd }}$ Pediatrics Department, "Grigore Alexandrescu" Emergency Children's Hospital, \\ Bucharest, Romania \\ ${ }^{2}$ Department of Endocrinology and Diabetes, Elias Hospital, Bucharest, Romania \\ 3"Carol Davila" University of Medicine and Pharmacy, Bucharest, Romania
}

\begin{abstract}
Growth hormone deficiency is a rare cause of low stature. Early recognition of the disease results in effective treatment, leading to a final height as closely as possible to the genetic target. The authors present the case of a 1 year 2 months old girl admitted for growth evaluation in our department. She had been previously diagnosed with isolated growth hormone deficiency in an Endocrinology Unit and was now sent to complete the investigations and undergo imaging studies. The laboratory investigations excluded other pathologies. The MRI showed adenohypophysis hypoplasia, thin hypophyseal stalk. Se is started on growth hormone substitution treatment with good results.
\end{abstract}

Keywords: growth hormone, low stature, hypophysis

\author{
Abbreviations \\ GHD: growth hormone deficiency \\ IGF-1: insulin growth factor 1 \\ IGFBP-3: insulin growth factor binding protein 3 \\ MRI: magnetic resonance imaging \\ $\mathrm{GH}$ : growth hormone \\ SD: standard deviation \\ BMI: body mass index \\ rhGH: recombinant human growth hormone
}

\section{INTRODUCTION}

Growth hormone deficiency (GHD) is a rare disease, characterized by inadequate growth hormone $(\mathrm{GH})$ secretion in the adenohypophysis. The prevalence of GHD is estimated at approximately $1 / 3-4000$ to $1 / 10,000(1,2)$. GHD in children may be present at birth (congenital) due to a number of genetic mutation and structural anomalies of the midline or acquired (infections, trauma, tumors, surgical procedures, radiation or idiopathic) (3). Severe congenital GHD of the newborn is a rare disease, but it can cause life-threatening hypoglycemias from the first week of life. Practical evi- dence-based approach to the diagnosis of GHD in the newborn are scarce in the literature (4). GHD is either isolated or associated with other pituitary deficits $(1,3)$.

The clinical picture of GHD includes growth retardation with low stature and delayed maturation (3). Other early signs may be micropenis or prolonged conjugated hyperbilirubinaemia. Although length at birth is usually within the normal centile ranges, postnatal growth failure can begin early and be profound, apparent within the first few months of life (5). GH levels should be measured in any baby with severe or symptomatic hypoglycaemia for which another cause is not obvious. Levels of 
less than $20 \mathrm{ng} / \mathrm{ml}$ would suggest GHD in the newborn $(5,6)$. In children with growth failure in whom other causes have been excluded, low IGF-1 and IGFBP-3 levels may indicate GHD, particularly if levels are below -2 SD. Serum IGF-1 is widely used as a biomarker, even though it correlates weakly with clinical endpoints in GH treatment. GH stimulation tests may be undertaken according to standardized protocols $(5,7,8)$. The evaluation of the shape and height of the pituitary gland by magnetic resonance imaging (MRI) is an additional tool for the diagnosis of GHD. In patients with congenital GHD, MRI has revealed morphological abnormalities such as pituitary hypoplasia, absence of the stalk and ectopia of the posterior pituitary. The presence of the later confirms this diagnosis and is predictive of multiple anterior pituitary deficiencies $(9,10)$. IRM is also an useful tool in predicting treatment response (11).

Short stature may place children at risk for bullying, social immaturity, and low self-esteem (12). In adults the consequences are psychological (low self esteem, depression, anxiety), but also metabolic (altered body composition, osteoporosis, low muscle mass, increased visceral adiposity, insulin resistance, high LDL-cholesterol and triglyicerides) $(13,14)$.

Growth hormone is needed for early infant growth (15). Children with GHD should be started on recombinant human growth hormone ( $\mathrm{rhGH})$ as soon as the disorder is recognized to optimize growth potential. The primary objectives of the therapy are normalization of height during childhood and attainment of normal adult height. GH should be administered subcutaneous, on a daily basis, in the range of $25-50 \mu \mathrm{g} / \mathrm{kg} / \mathrm{day}$, the dose being adapted according to clinical evolution and IGF-1 values. The treatment is discontinued in the transition period, when the patient may require retesting to see if GH is needed as an adult $(6,13,16)$.

Although the treatment is generally recommended after the age of three, in selected cases of severe congenital GHD, delaying treatment may result in severe height deficit, very difficult to compensate later on, with significant psychological consequences in a severely stunted child.

\section{CASE PRESENTATION}

One year two months old girl is admitted to the $3^{\text {rd }}$ Pediatrics Department of "Grigore Alexandrescu" Emergency Children's Hospital in order for growth retardation investigations to be completed. From her personal history we learned she was diag- nosed with isolated growth hormone deficiency at the age of one in the Endocrinology and Diabetes Department of Elias Hospital. Her family history revealed a 11 years old sister diagnosed with GHD at the age of 4 with good response to substitution treatment and the mother with severe low stature (-3.3 SD). The child is in a foster home from the age of 3 weeks and has good nutritional and affective support.

On clinical examination, the patient was in good general condition, infantile phenotype (fig. 1), severe low stature height $=62 \mathrm{~cm}(-5.6 \mathrm{SD})$, weight $=6,000 \mathrm{~g}, \mathrm{BMI}=15.6 \mathrm{~kg} / \mathrm{m}^{2}(\mathrm{pc} 10-25)$, pale, no hyperpigmentation or discoloration, well represented, troncular adipose tissue, with unremarkable findings on examination of the respiratory, cardiovascular and digestive systems, normal external genitalia, Tanner 1, no polyuria-polydipsia syndrome, anterior fontanel $2 / 1 \mathrm{~cm}$, age appropriate psychomotor development.

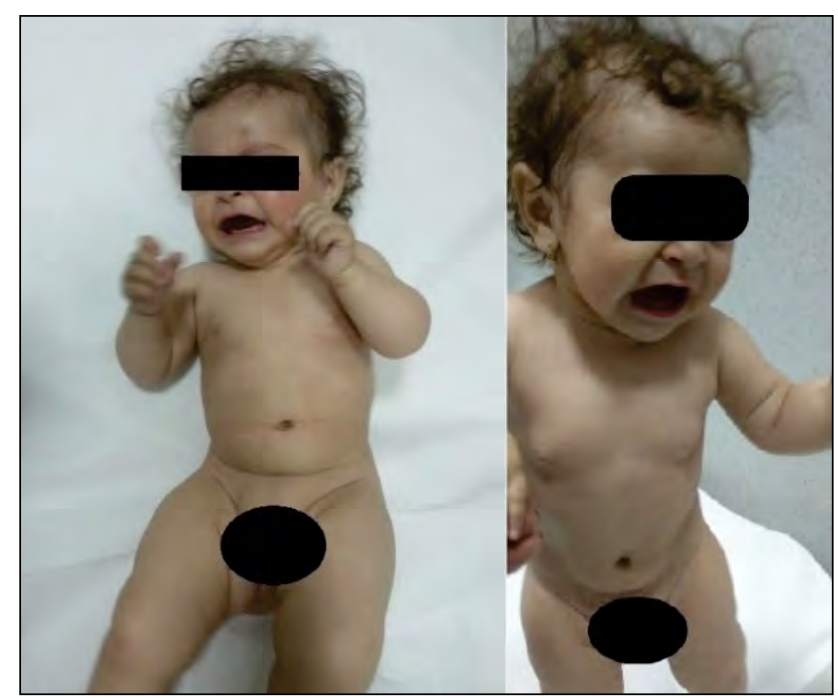

FIGURE 1. Patient's phenotype (infantile facies, troncular subcutaneous tissue)

The laboratory investigations showed mild hypochromic, microcytic anemia $(\mathrm{Hgb}=10.4 \mathrm{~g} / \mathrm{dl}$; Serum iron $=31 \mu \mathrm{g} / \mathrm{dl}$ ), no inflammatory syndrome, mild hypercholesterolemia, no biological malabsorption syndrome. The IgA-anti transglutaminase antibodies were normal $=1.40 \mathrm{U} / \mathrm{ml}(0-10$ $\mathrm{U} / \mathrm{ml}$ ), the sweat test $=56 \mathrm{mmol} / 1 \mathrm{NaCl}$ (normal value), specific IgE-s for different foods were normal. Hypothalamic-pituitary axis examination failed to diagnose other deficits. The laboratory investigations are depicted in table 1.

Non-dominant hand x-ray (Fig. 2) showed retarded bone age, approximately 9 months delay (according to Greulich-Pyle classification). 
TABLE 1. Patient's laboratory investigations

\begin{tabular}{|l|c|c|}
\hline Investigation & & Normal value \\
\hline Serum proteins (g/dl) & 6.6 & $5.5-7,5$ \\
\hline Total cholesterol (mg/dl) & $\mathbf{2 2 2}$ & $140-200$ \\
\hline Serum calcium (mg/dl) & 10.10 & $8.4-10.2$ \\
\hline $25-\mathrm{OH}$ Vitamin D (ng/ml) & 48.10 & $30-70$ \\
\hline Cortisol (ng/ml) & 201 & $54.94-287.56$ \\
\hline GH (ng/ml) & $\mathbf{0 . 0 5}$ & $0-8$ \\
\hline IGF-1 (ng/ml) & $\mathbf{1 5}$ & $55.00-327$ \\
\hline TSH (ulU/ml) & 5.02 & $0.7-5.97$ \\
\hline freeT4 (ng/ml) & 59.20 & $49.866-123.039$ \\
\hline Prolactin (ng/ml) & 35.75 & $5-35$ \\
\hline
\end{tabular}

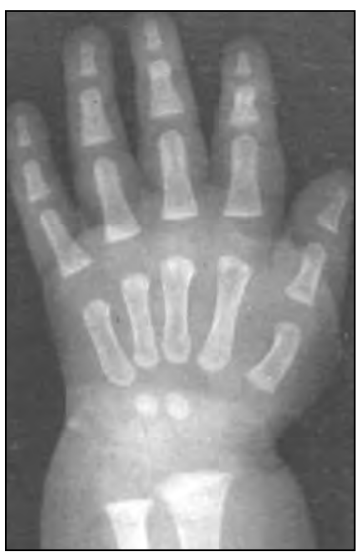

FIGURE 2. Bone age $=6$ months

The patient underwent hypothalamic-pituitary MRI (according to the national diagnosis and treatment protocol) which revealed adenohypophysis hypoplasia - small dimensions 5.1/9/1.5 mm, volume $35 \mathrm{~mm}^{3}$ (normal volume for age: $119 \pm 36$ $\mathrm{mm}^{3}$ ) - fig. 3 and filiform pituitary stalk - fig. 4 .

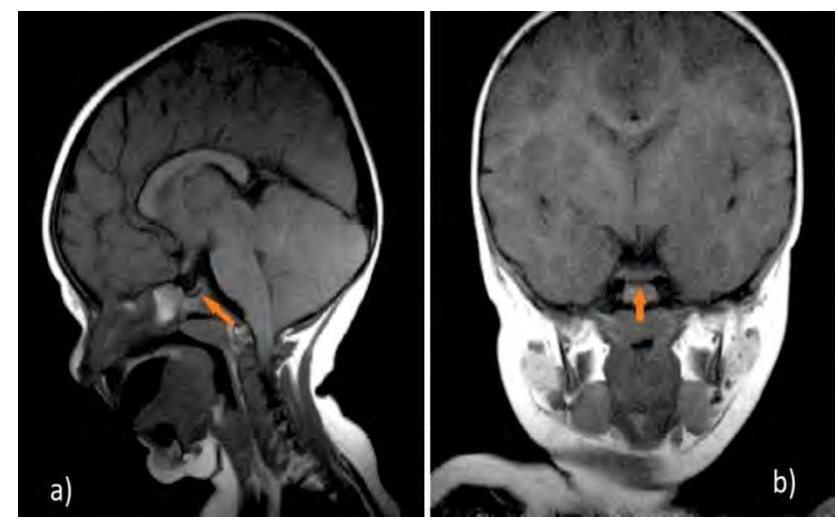

FIGURE 3. Hypothalamo-pituitary MRI: small dimensions adenohypophysis, a) Sagital section, T1 signal, b) Coronal section, T1 signal

The investigations confirmed the diagnosis of idiopathic GHD. The patient is started on subcutaneous Somatropinum $0.035 \mathrm{mg} / \mathrm{kg} / \mathrm{zi}$, daily regimen, 7/7 with good initial results, under clinical supervision in the Endocrinology and Diabetes Unit of Elias Hospital.

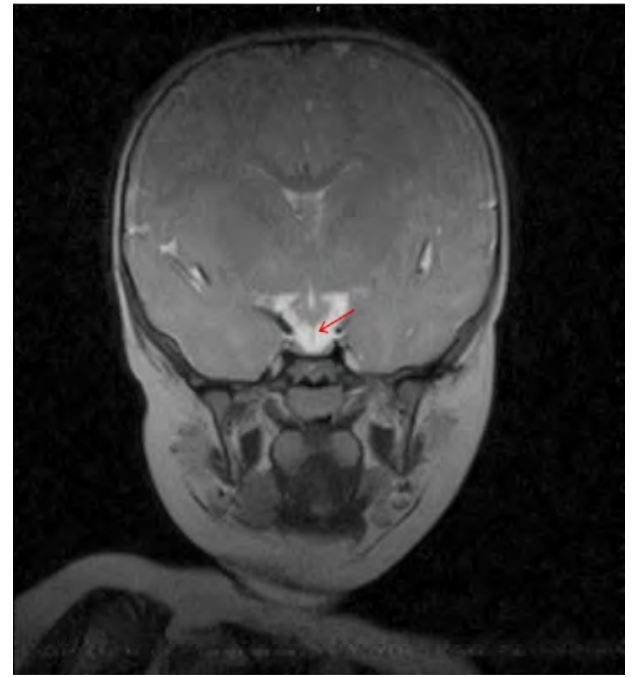

FIGURE 4. Hypothalamo-pituitary MRI (coronal section, T2 signal): filiform pituitary stalk

\section{DISCUSSIONS}

Low stature is defined as absolute height below two SD for age and sex (17). Recommended anthropometric standards for height are comprised in the synthetic curves for Romania, published in Acta Endocrinologica in 2016 (18). GHD is a rare, but important cause of low stature, with a prevalence of approximately 1:4,000 during childhood (1). GHD may be isolated or associated with other pituitary deficits. The diagnosis is based on a combination of phenotypic traits, proof of GH deficiency on challenge tests, low IGF-1 values, x-ray of the non-dominant hand and hypothalamic-hypophyseal MRI (19).

The case presented is the prototype of GHD in a normal weight child with family history of GHD and severe, well-proportioned low stature, IGF-1 low for age, delayed bone age and pituitary hypoplasia on MRI.

The finding of a familial case of pituitary stalk interruption suggests a genetic origin (9). Mutations in the GH-1 gene have been identified in patients with isolated GHD. Tsubahara et al describe two siblings with isolated GHD born from nonconsanguineous healthy parents. Both siblings had neonatal hypoglycemia, were diagnosed with GHD in the first year of life, flat $\mathrm{GH}$ response, normal MRI, the IGF-1 normalised with treatment, final height was above family prediction. GH1 gene in all family members was analysed. The father and both siblings had a deletion SNP in the 5'UTR of GH-1 - rs 11568827 and the mother and both siblings an inversion SNP in the 5' UTR of GH-1 rs 11568828 . So isolated GHD in this kindred is caused by the interplay of two SNPs of the 5'UTR of GH-1, one inherited from each parent (20). The 
patient presented, her sister and possibly her biological mother most likely share a common genetic trait. Testing was not available.

The literature describes the usefulness of MRI as a diagnostic tool, this investigation being essential in our case too.

Precocious treatment very much improves the growth outcome and final height and is completely reimbursed by the National Health Ministry according to a national standardized protocol (21). In severe cases of GHD, compensating metabolic anomalies secondary to GHD is an important issue in the management of these cases. Considering the shared familial diagnosis in our case as soon as the diagnosis of GHD was set, the substitution treatment was initiated hoping for an optimal endpoint height. Statistically significantly larger SDS for height values were reported for rhGH-treated children with GHD (22). Patients with congenital isolated GHD who do not receive early and regular replacement treatment are prone to lag in achieving normal height and suffer from educational and vocational handicaps (23). Health-related quality of life may improve as an additional benefit of the $\mathrm{GH}$ treatment in children with short stature (24).

\section{CONCLUSIONS}

Low stature is the most frequent form of presentation in patients with GHD. It can be the main complaint or the doctor may diagnose it in a patient presenting with unrelated pathology. Close monitoring of growth is an important indicator of general health and easily accessible to any clinician. The responsibility to set the diagnosis of low stature and initiate the algorithm for etiology is often in the charge of the pediatrician. In case of GHD, an early diagnosis and quick initiation of substitution treatment gives the patient the chance of an excellent prognosis regarding growth potential.

\section{Conflict of interest: none declared Financial support: none declared}

\section{REFERENCES}

1. Stanley T. Diagnosis of growth hormone deficiency in childhood. Curr Opin Endocrinol Diabetes Obes. 2012 Feb;19(1):47-52;

2. Dattani M., Kumaran A. Growh Hormone Deficiency - Difficulties in Diagnosis and Management. Eur. Endocrinol., 2008; 4(2):90-2;

3. Bozzola M, Meazza C. Growth Hormone Deficiency: Diagnosis and Therapy in Children. In: Restricted Growth - Clinical, Genetic and Molecular Aspects. InTech; 2016.

4. Binder G, Weidenkeller M, Blumenstock G, Langkamp M, Weber K, Franz AR. Rational approach to the diagnosis of severe growth hormone deficiency in the newborn. J Clin Endocrinol Metab. 2010 May;95(5):2219-26;

5. Ogilvy-Stuart AL. Growth Hormone Deficiency (GHD) from Birth to 2 Years of Age: Diagnostic Specifics of GHD during the Early Phase of Life. Horm Res 2003;60(suppl 1):2-9

6. GH Research Society. Consensus guidelines for the diagnosis and treatment of growth hormone $(\mathrm{GH})$ deficiency in childhood and adolescence: Summary statement of the GH Research Society. J Clin Endocrinol Metab. 2000 Nov;85(11):3990-3;

7. Johannsson G, Bidlingmaier M, Biller BMKet al. Growth Hormone Research Society: Growth Hormone Research Society perspective on biomarkers of GH action in children and adults. Endocr Connect. 2018 Mar;7(3):R126-R134;

8. Ranke MB, Schweizer R, Elmlinger MW, Weber K, Binder G, Schwarze CP, Wollmann HA. Significance of basal IGF-1, IGFBP-3 and IGFBP-2 measurements in the diagnostics of short stature in children. Horm Res 2000;54:60-68;

9. Argyropoulou M, Perignon F, Brauner R, Brunelle F. Magnetic resonance imaging in the diagnosis of growth hormone deficiency. J Pediatr. 1992 Jun;120(6):886-91;

10. Bozzola M, Adamsbaum C, Biscaldi I, Zecca M, Cisternino M, Genovese E, Richard I, Kalifa G, Chaussain JL. Role of magnetic resonance imaging in the diagnosis and prognosis of growth hormone deficiency. Clin Endocrinol (Oxf). 1996 Jul;45(1):21-6;

11. Kara Ö, Esen I, Tepe D, Gülleroğlu NB, Tayfun M. Relevance of Pituitary Gland Magnetic Resonance Imaging Results with Clinical and Laboratory Findings in Growth Hormone Deficiency. Med Sci Monit. 2018 Dec 30;24:9473-8;

12. Cohen $P$, Rogol AD, Deal $C L$ et al. Consensus Statement on the Diagnosis and Treatment of Children with Idiopathic Short Stature: A
Summary of the Growth Hormone Research Society, the Lawson Wilkins Pediatric Endocrine Society, and the European Society for Paediatric Endocrinology Workshop. J Clin Endocrinol Metab. 2008, 93, 4210-4217;

13. Snyder P, Cooper D, Martin Kathrin A. Growth hormone deficiency in adults - UpToDate (https://www.uptodate.com/contents/growthhormone-deficiency-in-adults);

14. Bradley S. Miller. Growth Hormone Deficiency (www. magicfoundation.org/);

15. Wit JM, van Unen H. Growth of infants with neonatal growth hormone deficiency. Arch Dis Child. 1992 Jul;67(7):920-4;

16. Head J, Levy R.A. Growth Hormone Deficiency. NORD National Organisation for Rare Disorders (https://rarediseases.org/rarediseases/growth-hormone-deficiency/);

17. Rogol A, Snyder P, Hoppin A. Causes of short stature - UpToDate (https://www.uptodate.com/contents/causes-of-short-stature).

18. Pascanu I, Pop R., Barbu CG et al. Development of Synthetic Growth Charts for Romanian Population. Acta Endocrinol. 2016;12(3):309-18;

19. Pedicelli S, Peschiaroli E, Violi E, Cianfarani S. Controversies in the definition and treatment of idiopathic short stature. J Clin Res Pediatr Endocrinol. 2009;1(3):105-15;

20. Tsubahara M, Hayashi Y, Niijima S, Yamamoto M, Kamijo T, Murata Y, Haruna H, Okumura A, Shimizu T. Isolated growth hormone deficiency in two siblings because of paternal mosaicism for a mutation in the GH1 gene. Clin Endocrinol (Oxf). 2012 Mar;76(3):420-4; 1301/500/2008 cu modificarile si completarile ulterioare (www.cnas.ro).

22. Takeda A, Cooper K, Bird A, Baxter L, Frampton GK, Gospodarevskaya E, Welch K, Bryant J. Recombinant human growth hormone for the treatment of growth disorders in children: a systematic review and economic evaluation. Health Technol Assess. 2010 Sep;14(42):1-209;

23. Ben-Nun Yaari E, Kauli R, Lilos P, Laron Z. Health and Lifestyle of Adult Patients with Congenital Isolated Growth Hormone Deficiency Treated in Childhood. Isr Med Assoc J. 2019 Mar;21(3):189-193;

24. Butler G, Turlejski T, Wales G, Bailey L, Wright N. Growth hormone treatment and health-related quality of life in children and adolescents: A national, prospective, one-year controlled study. Clin Endocrinol (Oxf). 2019 May 11. (Epub ahead of print).
21. Lista protocoalelor terapeutice aprobate prin Ordinul MS/CNAS nr. 